\title{
Decision-Making and its Social-Cultural Environments: A Proposed Research Model
}

\author{
Frederick G. Kohun and Robert Joseph Skovira \\ Robert Morris University, Moon Township, PA, USA
}

\author{
Kohun@rmu.edu Skovira@rmu.edu
}

\begin{abstract}
The paper presents a research model for understanding decision-making assumed to being done within decision-making situations contextualized within a multilayered social-cultural environment which includes a national social-cultural environment, an organizational matrix, a professional worldview, and a familial environment influencing behavior, and for this essay, decisionmaking. These social-cultural matricies have various dimensions, for example, power distance and uncertainty avoidance. The various levels consist of multiple communities of discourse and practice, that is, social group or networks with attending meaning-systems, vocabularies, and practices. These communities influence communicative and decision-making styles. People exhibit these styles within decision-making situations which, in this paper, are located within organizations, or companies.
\end{abstract}

Keywords: decision making, culture, social-cultural environment, decision-making situation, decision styles, research framework

\section{Introduction}

Especially now, organizational decision-making happens within a global arena among multiple companies embedded in their own national social-cultural environments (cultural matrices). Global decision-making situations test managers" "social/cultural IQ" (Harvey, Fisher, McPhail, \& Moeller, 2009, p. 358).

The essay follows Gert Hofstede's proposition (Hofstede, Hofstede \& Minkov, 2010) and others (Gaenslen, 1986; Ladbury \& Hinsz, 2009; Müller, 2009; Zakania \& Cogburn, 2008) that people act within the allowances and restrictions of their multilayered social-cultural environments, broadly speaking, their national cultures. That is, for this essay, every decision, every decisionmaking situation, and every decision-maker are contextualized, especially, by their national multilayered and multidimensional social-cultural environments. Differences are meaningful in a

Material published as part of this publication, either on-line or in print, is copyrighted by the Informing Science Institute. Permission to make digital or paper copy of part or all of these works for personal or classroom use is granted without fee provided that the copies are not made or distributed for profit or commercial advantage AND that copies 1) bear this notice in full and 2) give the full citation on the first page. It is permissible to abstract these works so long as credit is given. To copy in all other cases or to republish or to post on a server or to redistribute to lists requires specific permission and payment of a fee. Contact Publisher@InformingScience.org to global arena.

The problematic for this essay is the relation of a decision-making situation and its decision-to-be-made to the cultural (meaning-system) matrix (Dewey, 1986) surrounding and framing the situation. The paper's argument is that a describing and analyzing of a decisionto-be-made necessarily includes its decision-making situation as embedded in its 
social-cultural environment, a social-cultural web (Geertz, 1973) which locates the decision and any consequential actions.

The essay proposes a model for doing research into decision-making processes and situations with the purpose of providing explanations of decision-making based upon systems of meanings (culture, information) framing decisions-to-be-made. The systems of meanings are cultural environments inferred by the decisions, and the decision-making situations. Theses social-cultural environments are informational structures (Skovira, 2004) of difference which may provide a better explanation of decision-making (Gaenslen, 1986, p. 80-81).

The proposed research framework which links culture and decision making includes layers of social-cultural environments (cultural contexts), and their various dimensions: especially power distance, uncertainty avoidance (Hofstede, 1980; Hofstede, Hofstede \& Minkov, 2010), high to low modes of communicating (Hall, 1976, 1982), and decision making styles (Kluckhohn, 1951; Rowe \& Mason, 1987). These contexts act as situational filters for any decision-making process.

The multi-layered social-cultural environments (cultural contexts) include national level, organizational level, professional level, and familial level (ethnic, religious, gender, and class affiliation) as worldviews. High context of communication cultures are those in which information, meaning of actions and messages is mostly tacit shared. Low context of communication cultures are individualized and in which information, meaning of actions and messages is explicit, individualized and in need of constant explanation (Hall, 1976, 1982).

\section{Decisions-to-be-made and Decision-making Situation}

When studied as a cultural insider, decision making is mysterious; when you are a cultural outsider, it seems as if it is impossible. Because human beings are social-cultural beings, living in multilayered social-cultural environments, their decisions are social-cultural object or artifacts, informing objects. There are all kinds of decisions, from the simple to the complex, the straightforward to the convoluted. Most everyday decisions are interesting phenomena. The most complex, and thus the most interesting, are the decisions made that affect strategic outcomes. We start with a series of interesting questions about the relationship of culture to decision-making. What effect does culture have on decisions and decision-making? Does culture determine the nature of a decision, and what makes a good decision? Do persons of other cultures view problems differently? Is the notion of information different for members of different cultures? Is decision making the same across cultures? Are solutions culturally consistent? Are there any relevant heuristics to help answer or to put these questions into perspective?

The effectiveness of decision making within various cultural situations can be argued as the result of a decision making style that is both culture and language sensitive. One such bridge linking culture to decision making is communication via a taxonomy of contexts.

We make decisions to solve problems or resolve issues. Problems or issues surface as a sense of discontinuity between expectations and actual events and outcomes within a specific situation contextualized by social-cultural environments. A problem or issue focuses the need for making a decision (Huber, 1980). A cross cultural, global, situation increases the complexity of the decision-making process. Decision-making in any social-cultural context is a many faceted process. These facets include the nature of the decision-to-be-made, the attributes of a decision, its situational context, its complexity, the judgments and actions, objectives and goals, solutions, and decision- making styles ( Morris, 1977; Huber, 1980; Hill et al., 1979; Moody, 1983; Rowe \& Mason, 1987). 
Decision-making is a response to a problem that needs to be solved and leads to the action taken to change the problematic situation. A decision is an outcome of problem-solving. Decisionmaking is a judgment about the appropriate measures to rectify perceived problems. All judgments or decisions are situational. Decision-making is dependent not only upon the decision maker but also upon the situation, and the multiple factors impacting the situation. This entire process is immersed in a welter of social-cultural influences. Every aspect of a decision making situation -- the problem, the judgment, the decision maker, the styles of perceiving and thinking, and lastly, communicating -- is affected by culture.

Attributes of a "quality" decision are 1) knowledge of alternative choices and outcomes; 2) knowledge of needs fulfilled and values underlying a particular choice; 3) costs and benefits of a decision; 4) pursuit of complete information and knowledge; 5) awareness of subsequent information impacting on the decision; 6) review of all consequences of all alternative actions; and 7) planned alternative ways for implementation in minimize risk (Janis \& Mann, 1977, p.11).

Decisions are always made within a situation. The decision-making situation is always something to be controlled. Control is sought via the identification of assumptions and constraints. These usually mark the "current" boundaries of the situation. Every situation is a structure and a focus (Rowe \& Mason, 1987).

Making decisions, especially business decisions, is a complex activity. Complexity is the spice of life except when making a decision. Complex situations are uncertain arenas of behavior. Many decision-making techniques aim at reducing ambiguity and uncertainty by reducing the complexity of the problem.

A decision relies on having multiple avenues to use to accomplish the intended outcome. Making a decision or making a judgment about a specific course of action means choosing the most suitable path from among several to achieve this. The decision process consists of four stages: intelligence, design, choice, and implementation (Turban, 1990, p. 32).

How do you know you have a problem? It usually surfaces as a sense of discontinuity between expectations and actual events and outcomes within a specific situation. What is does not match what should be. In terms of an organization's information system, a problem shows itself when there are real or perceived differences between a system's objectives and its actual performances. While there are elements of problematic situations that are objective to the persons involved, people also bring many things (social-cultural contexts) to the generation of problems (Young, Becker \& Pike, 1970, p. 97). Types of problems can range from the structured to unstructured, from the programmed to nonprogrammable ones.

The concept of bounded rationality (Simon, 1977) is a perspective by which a problem's conceptual space is defined and identified by making explicit any constraints and by making limiting assumptions. Because individuals cannot have perfect knowledge of the information needed to solve the problem or make the decision, the bounded rationality approach reduces uncertainty and probabilistic thinking.

Solutions to problems, decisions, the results of decision making activities, are models of how one conceives of the whole decision making situation. These solutions are in essence modes of thinking and discourse involving people, thinking, tasks and actions. The modes of thinking and discourse reveal themselves through narration and list (O'Banion, 1992; Sontag, 2009). 


\section{Research Model for Culturally Framed Decision-Making}

The research model (see the taxonomy in Figure 1 below) for describing and analyzing decisionmaking situations and their decisions-to-be-made consists of a set of methodological set of categories (only four are given here) of social-cultural environments (culture). The predominant social-cultural categories or frames of the model are the national, the organizational, the professional, and the familial. These are infoscapes (Skovira, 2004) of action, decision-making, vocabulary-use, and practices. They represent a multilayered (Hofstede, Hofstede \& Minkov, 2010, pp. 17-18) cultural matrix.

\begin{tabular}{|c|}
\hline Research Model for Culturally Framed Decision Making \\
Social-cultural environments \\
Infoscapes \\
Communities of discourse and practice \\
Frames: societal, organizational, professional, familial \\
\hline High-low contexts of communicating \\
Situations, vocabularies, practices \\
\hline Dimensionalities of social-cultural environments \\
Power distance, uncertainty avoidance, masculinity-femininity \\
Individualist-collectivist, long-term - short-term orientation \\
Decision-making styles \\
Directive, analytical. Conceptual, behavioral \\
\hline Modes of doing and saying \\
Narratives and lists \\
\hline Decision-making situations \\
Decisions-to-be-made
\end{tabular}

Figure 1: Research Model Taxonomy

A descriptive and analytic category of the research model is the social-cultural environment we reference as our national culture. We should not be surprised to learn that everything we do is culture, that culture is what we do and are. There are hundreds of definitions of culture (Spradley $\&$ McCurdy, 1972). Culture consists of the knowledge, belief systems, and behaviors everyone needs in order to live successfully in a society (Spradley, 1972, pp. 6-8; Spradley \& McCurdy, 1972). Different cultures enculturate people into different ways of thinking and problem solving. A culture is a set of frames or a series of channels of different perceptual and conceptual constructs (Gladwin, 1974, p. 29; Goffman, 1974).

Culture is representational forms of thinking and action, for doing things in the world and responding to culturally defined states-of-affairs (Hall, 1976, p. 13). Culture, therefore, is the patterns by which we consider, evaluate, say and do things. At a culture's center are the systems of ideas and attendant systems of valuing into which individuals are enculturated (Kluckhohn, 1951, 
pp. 5, 86). Culture is the ways that model a group's transactions with its circumstances. It creates and structures a group's self image much as an individual's self image is manufactured by personality (Hofstede, 1980, pp. 25-26; Hofstede, Hofstede \& Minkov, 2010).

One can never be sure about how cultural identities surface...e.g. Slovak. Ethnic identities or subcultures are the outcomes of a transactional process with the surrounding dominant culture as well as competitive subcultures. With the advent of the European Union and its member nation states - it could have been argued that historic cultural ethnic determinism would have been replaced by European Union identity. However, the global economic crisis beginning in 2008 led to a resurgence ethnic member state nationalism at the expense of European Union identity.

A second descriptive and analytic category of the research model is the social-cultural environment we reference as our organizational culture. By definition as a social institution, any organization has a culture, and readily generates subcultures depending upon the organizational structure and functional areas. Organizational environments consisting of webs of meanings, situations, and vocabularies (language as "shared beliefs and values" (Van den Steen, 2010, p. 618) contextualize decision-making situations. It is assumed that because business organizations are within a culture, the organizational cultures are affected (Kilmann, 1989, p. 58). An organization's culture is symbolized by the unique artifacts, language, and behaviors as influenced and filtered by the organization's mission and objectives. Because of the artificial nature of any business organization, it is more than likely that the patterns and dimensions of a national culture are expressed within the organization by a different set of symbols. "Culture is the invisible force behind the tangibles and observables in an organization, a social energy that moves the people into action. Culture is to the organization what personality is to the individual--a hidden yet unifying theme that provides meaning, direction, and mobilization " (Kilmann, 1989, p. 50).

A third descriptive and analytic category of the research model is the social-cultural environment we reference as our professional culture. A person's professional association and discipline also contributes to as well as reinforces enculturated cultural patterns. The valuing system of a professional association or discipline is another socio-cultural filter of larger national patterns, dimension or frames. They institutionalize specific values. Identities are formed and maintained on the basis of profession, i.e., accountant, teacher, politician, physician, computer programmer.

A fourth descriptive and analytic category of the research model is the social-cultural environment we reference as our familial culture. The family as a social-cultural environment determines much of how we act, do and say things, and make decisions. This category includes ethnic, religious, and class identities or worldviews.

According to Hofstede (1980), dimensions of national culture and dominant value systems can be studied and understood by looking at the factors of power distance, uncertainty avoidance, individualism, and masculinity (to name only four of the dimensions) within any organization and profession, as well as family (Ladbury \& Hinsz, 2009, pp. 187-188; Sim, 2010; Hofstede, Hofstede \& Minkov, 2010).). Culture affects decision-making, for example, audit controls (Sim, 2010, p. 55).

Power distance is the idea of the function of hierarchy and power within a culture. This dimension is concerned with the fundamental inequality to be had in societies and especially organizations, which mainly being hierarchical, create a superior-subordinate relationship (Hofstede, 1980, p. 92; Hofstede, Hofstede \& Minkov, 2010, pp. 60-61). Culture, or meaning-systems, reflective of power relationships and avoidance of uncertainty show up in organizations which centralize or decentralize decision-making (Head, Yaeger, \& Sorensen, 2010, p. 45). 
Uncertainty avoidance is a dimension about people trying to avoid the vicissitudes or ambiguities of situations. There is a need for security and stability and risk-takers are not the norm. Coping mechanisms vary but the most significant is the use of rule-based or ritual behavior. Even in corporate organizations (Hofstede, 1980, p. 153; Hofstede, Hofstede \& Minkov, 2010, p. 191).

Individualism is a dimension of uniqueness, of seeing the self as the center of things and how the person relates to group identities; how the individual relates to the social group. Tonnies contributed the constructs of Gemeinshaft and Gesellshaft as high and low individual to group relationships (Hofstede, 1980, p. 213; Hofstede, Hofstede, \& Minkov, 2010, p. 92).

Masculinity is a dimension of how national cultures differ in terms of being masculine or feminine, either assertive or nurturing as an enculturation process. This dimension has been frequently discussed in the literature-particularly in business (Hofstede, 1980, p. 261; Hofstede, Hofstede, \& Minkov, 2010, p. 140).

Every social-cultural environment, and the cultural matrix as a whole is a communicative context: a high to low continuum. A high context culture, social-cultural environment is one of "common sense", where a basic assumption is that everyone understands even the slightest shrug of a shoulder, a wink, or blink. A low context environment is where everything is spelled out, and nothing is assumed about what others know (Hall, 1976, 1982) "'Context' is the information that surrounds an event and is inextricably bound up with the meaning of the event (Hall, 1976, p. 39; Hall \& Hall, 1987, p. 7; Zakania \& Cogburn, 2008, p. 116). Webs of significance, or culture (Geertz, 1972) contextualize decisions-to-be made and decision-making situations within highlow networks of communication (Hall, 1976; Zakania \& Cogburn, 2008, p. 116; Müller, 2009, p. 75).

Decision making styles (Hofstede, 1980, p. 101): autocratic, persuasive/paternalistic, consultative, and democratic have been implicitly discussed over the past thirty years. These dimensions have been refined within the context of management by, Rowe and Mason (1987) in their decision style model. They refined and identified four basic decision styles: directive, analytical, conceptual, and behavioral. National cultures influence decision-making, and cause differences in decision-making "styles" (Müller, 2009, p. 71). Culture establishes a significant ground for differences in leadership styles and decision-making styles (Yooyanyong \& Maenjohn, 2010, pp. 162-163). Both Hofstede's decision styles and the refined Rowe and Mason model are inherently culturally rooted.

Decision making is the result of a process of based in the framing of the problem through narrative (the culturally based context or story) and its symbiotic representation - the list (Young, Becker, \& Pike, 1970; O’Banion, 1992; Sontag, 2009).

\section{Summary and Concluding Remarks}

This paper proposed a framework that links culture and decision making. Attributes related to decisions and decision making framed in culture are presented as a foundation for the proposed model of cultural based decision-making that is illustrated in Figure 1 (above). Decision-making which involves people, thinking, tasks and action is suggested to be founded and affected by decision style, cultural decision making dimensions, and cultural framework. Research is currently underway to secure data as to if and to what extent the attributes and dimensions are culturally differentiated. The questions posed earlier as whether cultural filters frame how problems are viewed, whether the notion of information is the same across cultures, and if problem solutions are culturally consistent are the focus of this study to validate the proposed framework. In a 
global information rich society, the role of culture appears to be much of interest today as it was when Hofstede and Hall began their life's work.

\section{References}

Blodgett, J. G., Bakir, A., \& Rose, G. M. (2009). A test of the validity of Hofstede's cultural framework. Journal of Consumer Marketing, 25(6), 339-349.

Dewey, J. (1986). Logic: The theory of inquiry. In J. A. Boydston (Ed.), John Dewey: The later works, 1925-1953 (Vol. 12: 1938). Carbondale and Edwardsville: Southern Illinois University Press. (Original work published 1938).

Gaenslen, F. (1986). Culture and decision making in China, Japan, Russia, and the United States. World politics, 39,(1), 78-103.

Geertz, C. (1973). The interpretation of cultures. New York: Basic Books.

Goffman, E. (1974). Frame analysis: An essay on the organization of experience. Cambridge: Harvard University Press.

Hall, E. T. (1976). Beyond culture. Garden City, NY: Anchor Books, Doubleday.

Hall, E. T. (1982). The hidden dimension. New York: Doubleday.

Hall, E. T., \& Hall, M. R. (1987). Hidden differences: Doing business with the Japanese. New York: Anchor Books, Doubleday.

Harvey, M., Fisher, R., McPheil, R., \& Moeller, M. (2009). Globalization and its impact on global managers' decision processes. Human resources development international, 12(4), 353-370.

Head, T., Yaeger, T., \& Sorensen, P. (2010). Global organization structural design: Speculation and a call for action. Organization development journal, 28(2), 41-48.

Hill, P. H. et al. (1979). Making decisions: A multidisciplinary approach. Reading, MA: Addison-Wesley.

Hofstede, G. (1980). Culture's consequence: International differences in work-related values. Beverly Hills, CA: Sage Publications.

Hofstede, G., Hofstede, G. J., \& Minkov, M. (2010). Cultures and organizations: Software of the mind. New York: McGraw-Hill.

Huber, G. P. (1980). Managerial decision making. Glenview, IL: Scott, Foresman.

Gladwin, T. (1974). Culture and logical process. In J. W. Berry \& P.R. Dasen (Eds.), Culture and cognition: Readings in cross-cultural psychology. London: Methuen.

Janis, I. L., \& Mann, L. (1977). Decision making: A psychological analysis of conflict, choice, and commitment. New York: The Free Press.

Kilmann, R. H. (1989). Managing beyond the quick fix. San Francisco, CA: Jossey-Bass.

Kluckhohn, C. (1951). The study of culture. In D. Lerner \& H. D. Lassell (Eds.), The policy sciences. Stanford, CA: Stanford University Press.

Ladbury, J. L., \& Hinsz, V. B. (2009). Uncertainty avoidance influences choices for potential gains but not losses. Current Psychology, 28, 187-193

Moody, P. E. (1983). Decision making. New York: McGraw-Hill.

Morris, W. T. (1977). Decision analysis. Columbus, OH: Grid. 
Müller, R. (2009). Cultural differences in decision making in project teams. International Journal of Managing Projects in Business, 2(1), 70-93.

O’Banion, J. D. (1992). Reorienting rhetoric: The dialectic of list and story. University Park, PA: The Pennsylvania State University Press.

Rowe, A. J., \& Mason, R. O. (1987). Managing with style. San Francisco, CA: Jossey-Bass.

Sim, M. (2010). National culture effects on group evaluating internal control. Managerial Auditing Journal, 25(1), 53-78.

Simon, H. A. (1977). The new science of management decisions. Englewood Cliffs, NJ: Prentice-Hall.

Skovira, R. J. (2004). Using informational landscape as a model to understand information use and design within organizations. Issues in Information Systems, V(1), 308-314.

Sontag, S. (Ed.) (2009). A Barthes reader. Introduction by S. Sontag. New York: Barnes \& Noble. (Originally published 1982).

Spradley, J. P. (Ed.). (1972). Culture and cognition: Rules, maps, and plans. San Francisco: Chandler Publishing.

Spradley, J. P., \& McCurdy, D. W. (1972). The cultural experience: Ethnography in complex society. Chicago: Science Research Associates.

Sturtevant, W. C. (1974). Studies in ethnoscience. In J. W. Berry \& P. R. Dasen (Eds.), Culture and cognition: Readings in cross-cultural psychology. London: Methuen.

Van den Steen, E. (2010). On the origin of shared beliefs (and corporate culture). RAND Journal of Economics, 41(4), 617-648.

Watson, H. J., \& Sprague, R. H., Jr., (1989). The components of an architecture of DSS. In R. H. Sprague, Jr. \& H. J. Watson (Eds.), Decision support systems: Putting theory into practice (2nd ed.). Englewood Cliffs, NJ: Prentice Hall.

Yooyanyong, M. P. \& Maenjohn, N. (2010). Leadership styles of expatriate managers: A comparison between Americans and Japanese expatriates. The Journal of American Academy of Business, 15(2), 161-167.

Young, R. E., Becker, A. L., \& Pike, K. L. (1970). Rhetoric: Discovery and change. San Diego: Harcourt Brace Jovanovich.

Zakania, N. \& Cogburn, D. (2008). Webs of culture: Applying intercultural communication theory to understand distributed decision-making processes. International Business Research, 1(3), 115-123.

\section{Biographies}

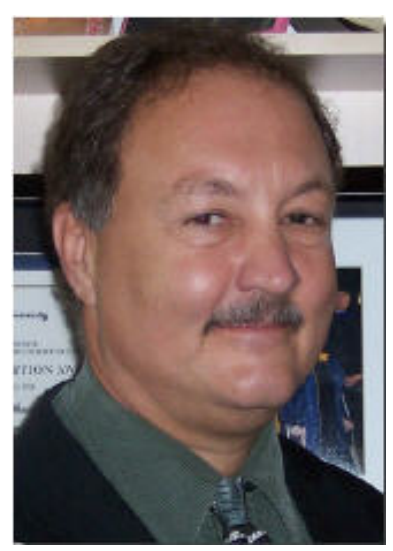

Frederick G. Kohun, Ph.D., Associate Provost and University Professor at Robert Morris University in Pittsburgh, Pennsylvania has more than 35 years experience as a professor, department head, and academic administrator in the economics, policy and information systems fields. He holds a bachelor degree in economics from Georgetown University, graduate degrees in economics and information science, from the University of Pittsburgh, and a Ph.D. in applied history in technology from Carnegie Mellon University. At Robert Morris University he led the design and implementation of eight technology based academic programs at the undergraduate and graduate level (including a doctoral program) as well as the attainment of ABET-CAC accreditation $\mathrm{He}$ is known both nationally and internationally from his numer- 
ous publications and presentations in health informatics, decision support, technological impact, and culture as well as his active involvement as an accreditation evaluator and team leader. In 2007, the International Association of Computer Information Systems named him the International Computer Educator of the Year.

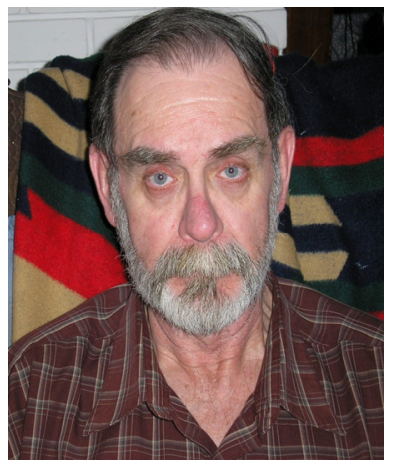

Robert Joseph Skovira is University Professor of Computer and Information Systems in the Department of Computer and Information Systems at Robert Morris University, Moon Twp (Pittsburgh) PA USA. He has taught undergraduate and graduate (MS) courses including Java Programming, Secure Programming, Global, Economic, Social, and Ethical Issues of Computing, Decision Support Systems, Information Design, and Ethical and Legal Issues of Technology. In the Doctor of Science program, he has taught Ethnography of Information Systems, Readings in Information Systems and Communications Research, and Writing the Proposal for Research courses. He has been a visiting professor at Comenius University, Bratislava, Slovakia, in 1997 and 2006. Research interests include the anthropology of information, information and information system use within organizations (the infoscape, politics of information, information system bias), cultural and moral frameworks of information and information use, decision making and knowledge management, informing objects, information design and thinking visually. 